\title{
O Discurso do Sujeito Coletivo: análise da percepção discente acerca do processo de ensino-aprendizagem no contexto da Pandemia de Covid-19
}

The Collective Subject Discourse: analysis of the student perception about the teaching-learning process in the context of the Covid-19 Pandemic

EI Discurso del Sujeto Colectivo: análisis de la percepción de los estudiantes sobre el proceso de enseñanza-aprendizaje en el contexto de la pandemia de Covid-19

\author{
Érica Cavalcante Lima \\ ORCID: https://orcid.org/0000-0003-4283-4022 \\ Universidade Federal do Ceará, Brasil \\ E-mail: ericalimaufc@bol.com.br \\ Francisco Levi Jucá Sales \\ ORCID: https://orcid.org/0000-0003-2860-3412 \\ Universidade Federal do Ceará, Brasil \\ E-mail: levijuca@gmail.com \\ Juliana Alice Costa Freire \\ ORCID: https://orcid.org/0000-0002-8198-4229 \\ Universidade Federal do Ceará, Brasil \\ E-mail: juliana_cfreire@ hotmail.com \\ Patrícia Helena Carvalho Holanda \\ ORCID: https://orcid.org/0000-0002-8233-1190 \\ Universidade Federal do Ceará, Brasil \\ E-mail: patrícia.holanda@gmail.com
}

\begin{abstract}
Resumo
A pandemia da Covid-19 impôs transformações ao processo de ensino-aprendizagem em todas as etapas da educação formal. De tal forma, rápida e sem precedentes, que as instituições acadêmicas têm buscado se ressignificar. A proposta deste artigo é apresentar os desafios e possibilidades da educação no contexto da pandemia, a partir das percepções dos alunos da disciplina de "Psicologia e Desenvolvimento da Aprendizagem na Adolescência", oferta nos cursos de licenciatura da Universidade Federal do Ceará (UFC), campi Fortaleza (CE), suscitando diálogos e reflexões sobre o processo remoto de ensino-aprendizagem, a teorização curricular crítico/reflexiva, formação problematizadora e interdisciplinar, utilizando como referencial as contribuições de Freire (1987), Pimenta (1999) e Silva (2005). Considerando a reinvenção do programa e as especificidades da disciplina, tomamos por instrumento de pesquisa a aplicação de questionário individual, em cuja análise utilizamos o método do Discurso do Sujeito Coletivo (Lefèvre, Marques, \& Lefèvre, 2003). Entendemos que o presente estudo evidenciou a importância de considerar os aspectos cognitivos, emocionais e culturais, com a finalidade de repensar o que já foi pensado, visando potencializar a força do processo educativo na formação dos alunos na construção de uma cidadania crítica e autônoma, com habilidade de viver e conviver em um mundo em constante mudança com mais humanidade.
\end{abstract}

Palavras-chave: Ensino-aprendizagem; Discurso do sujeito coletivo; Discentes; Ensino remoto; Covid-19.

\begin{abstract}
The Covid-19 pandemic has imposed transformations on the teaching-learning process at all stages of formal education. So quickly and without precedent, that academic institutions have sought to resignify themselves. The purpose of this article is to present the challenges and possibilities of education in the context of the pandemic, based on the perceptions of students in the discipline of "Psychology and Development of Learning in Adolescence", offer in the undergraduate courses of the Federal University of Ceará (UFC), Fortaleza campuses (CE), raising dialogues and reflections on the remote teaching-learning process, critical/reflective curriculum theorization, problematizing and interdisciplinary training, using as reference the contributions of Freire (1987), Pimenta (1999) and Silva (2005). Considering the reinvention of the program and the specificities of the discipline, we took as a research instrument the application of an individual questionnaire, in whose analysis we used the Collective Subject Discourse method (Lefèvre, Marques, \& Lefèvre, 2003). We understand that the present study showed the importance of considering cognitive, emotional and cultural aspects, with the purpose of rethinking what has already been thought, aiming to potentiate the strength of the educational process in the formation of students in the construction of a critical and autonomous citizenship, with the ability to live and live in a world in constant change with more humanity.
\end{abstract}


Keywords: Teaching-learning; Discourse of the collective subject; Students; Remote teaching; Covid-19.

\begin{abstract}
Resumen
La pandemia de Covid-19 ha impuesto transformaciones en el proceso de enseñanza-aprendizaje en todas las etapas de la educación formal. Tan rápido y sin precedentes, que las instituciones académicas han buscado resignificarse. El propósito de este artículo es presentar los desafíos y posibilidades de la educación en el contexto de la pandemia, a partir de las percepciones de los estudiantes en la disciplina de "Psicología y Desarrollo del Aprendizaje en la Adolescencia", oferta en los cursos de pregrado de la Universidad Federal de Ceará (UFC), campus Fortaleza (CE), planteando diálogos y reflexiones sobre el proceso de enseñanza-aprendizaje remoto, teorización curricular crítica/reflexiva, problematización y formación interdisciplinaria, tomando como referencia los aportes de Freire (1987), Pimenta (1999) y Silva (2005). Considerando la reinvención del programa y las especificidades de la disciplina, tomamos como instrumento de investigación la aplicación de un cuestionario individual, en cuyo análisis utilizamos el método del Discurso del Sujeto Colectivo (Lefèvre, Marques, \& Lefèvre, 2003). Entendemos que el presente estudio mostro la importancia de considerar aspectos cognitivos, emocionales y culturales, con el propósito de repensar lo ya pensado, con el objetivo de potenciar la fuerza del proceso educativo en la formación de los estudiantes en la construcción de una ciudadanía crítica y autónoma, con la capacidad de vivir y vivir en un mundo en constante cambio con más humanidad.
\end{abstract}

Palabras clave: Enseñanza-aprendizaje; Discurso de sujeto colectivo; Estudiantes; Enseñanza a distancia; Covid-19.

\title{
1. Introdução
}

A partir de março de 2020, ao ser decretada oficialmente a necessidade de isolamento social pelo governo estadual, a sociedade cearense iniciou o enfrentamento à pandemia da Covid-19, ocasionada pelo novo coronavírus, que, desde então, impôs mudanças radicais e sem precedentes em escala planetária, afetando profundamente os setores sociais, políticos e econômicos, nos quais se incluem todas as etapas da educação formal. Apesar das eventuais propostas de retorno às atividades presenciais, quando da relativa abertura proporcionada pela diminuição do número de casos da doença, grande parte do setor educacional vem, cautelosamente, mantendo-se no âmbito virtual perante uma realidade de incertezas, reforçada desde a desigualdade de acesso à internet e demais equipamentos necessários, até a circunstância da lenta política de vacinação nacional.

A proposta deste artigo é contribuir para a reflexão acerca da experiência do ensino superior no contexto pandêmico, considerando, principalmente, a percepção dos próprios alunos sobre a sua realidade (Freire, 1987), em processo de ensinoaprendizagem na modalidade remota, com aplicação de questionários e sua análise qualitativa através do método do Discurso do Sujeito Coletivo (DSC) (Lefèvre, Marques, \& Lefèvre, 2003). Visamos, ainda, compreender e superar os desafios metodológicos da construção de propostas curriculares efetivas e acessíveis a todos, à luz de uma teorização crítico/reflexiva, dialogando com Freire (1989) Pimenta (1999) e Silva (2005).

Quanto ao universo pesquisado, trabalhamos junto às duas turmas da disciplina de "Psicologia e Desenvolvimento da Aprendizagem na Adolescência”, sob nossa orientação, enquanto professores(as) titulares e alunos(as) da pós-graduação, cumprindo estágio de docência no semestre 2020.2 (setembro/2020 a abril/2021). A referida disciplina é ofertada a cursos de licenciatura da Universidade Federal do Ceará (UFC), campi de Fortaleza (CE), cidade epicentro da Covid-19 no Nordeste brasileiro.

De tal modo que, primeiramente, apresentamos a proposta e as peculiaridades da disciplina mencionada, incluindo características do perfil discente obtidas por meio da aplicação de questionário individual. Em seguida, tratamos mais detidamente acerca do método do DSC, ferramenta que utilizamos para a identificação da percepção dos alunos sobre o processo de ensino-aprendizagem no contexto de isolamento social. Por fim, revelando a perspectiva discente através das falas analisadas, discutimos sobre a experiência do processo de ensino-aprendizagem no contexto de pandemia. 


\section{A disciplina "Psicologia e Desenvolvimento da Aprendizagem na Adolescência": Proposta, Perfil Discentes e Peculiaridades.}

Diante do cenário de exceção apresentado pelas medidas sanitárias de contingenciamento da pandemia de Covid-19, o novo plano de reposição e reinvenção das atividades acadêmicas pretendeu atender às demandas de retorno do ensino, de acordo com o Plano Pedagógico Emergencial da Pró-Reitoria de Graduação (PROGRAD/UFC) e com o Plano Participativo da Faculdade de Educação (FACED/UFC). O referido plano foi concebido de modo a abrir a possibilidade de promover ajustes e adequações em face daquele originalmente adotado antes da irrupção da pandemia e da interrupção das atividades letivas, propondo a realização de atividades didáticas por meio de acesso remoto em Formato síncrono e assíncrono.

$\mathrm{Na}$ atividade síncrona, ministramos as aulas no formato de videoconferência, pela plataforma Google Meet, em tempo real, no horário regular e previsto na matrícula da disciplina, com exposição, debate e registro da frequência via Google Forms. Por outro lado, todas as aulas foram gravadas e disponibilizadas na plataforma acadêmica SIGAA-UFC aos estudantes, sendo possível acessá-las em formato assíncrono, bem como a resolução de um estudo dirigido tendo como base o texto referência do dia da aula, para garantir a presença diante de eventual falta à aula síncrona, dentre outras atividades avaliativas, como o relatório final sobre as palestras de convidados que compõem os seminários temáticos da disciplina. Foram utilizados, ainda, outros aplicativos para facilitar a comunicação e o compartilhamento de arquivos entre professores e alunos, como WhatsApp e Google Drive.

No entanto, para além das questões técnicas e metodológicas comuns a outras disciplinas ofertadas nesse contexto, é importante notar algumas peculiaridades da disciplina em questão. A primeira é a constatação de que, no atual currículo, tratase da única disciplina ofertada às licenciaturas de áreas específicas com essa temática e discussão. Por essa razão, trata da fase da adolescência, público do fundamental II e ensino médio, etapas de ensino que têm como pré-requisito a contratação de docentes formados nas disciplinas específicas, embora em nosso programa contemplamos algumas questões da psicologia e desenvolvimento da infância. Portanto, consideramos ainda maior a nossa responsabilidade em reforçar o seu caráter basilar, sobretudo para a futura experiência docente dos alunos.

Em síntese, a ementa da disciplina contempla uma breve introdução à psicologia, passando pelo conceito e características da adolescência, o seu desenvolvimento biológico, psicológico, afetivo e cognitivo. Também as crises na adolescência, os fatores psicológicos e os distúrbios no processo ensino-aprendizagem, considerando a percepção, a atenção, a motivação, a memória, a inteligência e, por fim, a avaliação da aprendizagem.

Para melhor traçarmos o perfil dos alunos das duas turmas da disciplina, aplicamos, ao final da mesma, um questionário individual, que iniciou com a apresentação dos Termos de Consentimento Livre e Esclarecido (TCLE), com o intuito de fornecer aos alunos que se voluntariam a participar da pesquisa todos os esclarecimentos acerca da nossa investigação, a medida que foi apresentado os seus riscos e benefícios, ofertando elementos para sua tomada de decisão de participação (ou não), de fato livre e consciente. Os alunos foram informados, ainda, que podiam retirar seu consentimento no momento que desejasse, sem ter necessidade de justificar, e de, por ter tomado a decisão de não responder o questionário, não sofreriam qualquer crítica ou prejuízo ao seu processo na disciplina. Todos esses cuidados foram tomados, devido o questionário consistir no principal instrumento utilizado para a análise que intentamos no presente artigo. Com perguntas objetivas de identificação, que transcrevemos a seguir, e as demais subjetivas, das quais trataremos adiante:

1. Idade: ( ) $18-27$ ( ) $28-37$ ( ) $38-47$ ( ) $48-58$ ( ) acima de 58 anos

2. Curso:

3. Trabalha e estuda ( ) Estuda ( )

4. Assiste à aula através de qual equipamento?

$\begin{array}{lll}\text { ( ) Celular ( ) Notebook ( ) Tablet } & \end{array}$

5. Acesso à Internet:

( ) Em casa $\quad$ ( ) Em outros lugares 
As duas turmas somavam um total de 63 alunos, tendo 44 desses respondido ao questionário aplicado sem obrigatoriedade. A maioria dos alunos tem entre 18 e 27 anos de idade, dentre os quais 29 apenas estudam e 15 conciliam estudo e trabalho, sendo que todos assistem às aulas em casa, por meio de celular e/ou notebook. Outra questão é a característica heterogênea das turmas da disciplina, no que diz respeito à proveniência de alunos dos mais diferentes cursos, que entendemos como oportunidade privilegiada para a promoção de discussões interdisciplinares e interculturais, considerando a diversidade formativa que integra as duas turmas aqui analisadas, com alunos oriundos de 14 cursos diferentes da UFC: Ciências Biológicas, Química, Física, História, Matemática, Teatro, Dança, Música, Filosofia, Geografia e Letras (Português/Inglês/Espanhol/Francês).

Nessa perspectiva, também planejamos um programa de seminários ministrados por especialistas convidados, com temas transversais que preconizassem maior poder de alcance e transformação, a saber: "Práticas de educação integral e protagonismo adolescente", "História, saúde e educação: problemáticas e diálogos para a educação básica no Brasil", "Saúde mental em contexto de pandemia" e "Sexualidade e gênero na escola: uma discussão necessária", trazendo, ainda, discussões relacionadas ao meio ambiente, educação inovadora e por projetos.

Ao mediarmos essa discussão juntos aos alunos sobre as suas realidades, aproximamo-nos da concepção de uma educação que integra diferentes sujeitos e seus respectivos contextos e identidades híbridas. Como seres humanos, somos naturalmente diversos e interdisciplinares, seja nos aspectos biológicos e psíquicos, sociais e culturais. Esse pensamento e conhecimento complexo, inerente à própria vida, em que tudo está conectado, foi substituído pela compreensão cientificista de um conhecimento especializado, fragmentado e reproduzido por meio do currículo e da divisão das disciplinas, as quais, antes de tudo, são ciências específicas. Através de práticas educativas críticas e emancipatórias, de conscientização social, que consideram as opções e interações de sujeitos que se referem a padrões culturais diferentes, acabamos por desenvolver estratégias de superação de qualquer tipo de discriminação, exclusão e sujeição.

Silva (2005) define que, no currículo, cada conhecimento contribui para a formação de um tipo específico de sujeito. De tal modo, nas teorias de currículo, a pergunta “o quê?" nunca está separada de "o que é que eles devem ser?", ou melhor, “em que eles ou elas devem se tornar?". Enfim, um currículo busca precisamente modificar as pessoas que vão "seguir aquele currículo." Percebendo, pois, o currículo sob as concepções natural e crítica, vislumbramos significados que transcendem a literal "grade" curricular engessada dos programas e teorias tradicionais. O currículo é território, relação de poder, trajetória e autobiografia, e nele se forja nossa identidade. Sendo também texto e discurso, o currículo é um documento de identidade. Não à toa, buscamos ouvir, durante e após a disciplina, os discentes: "aqueles e aquelas que devem se tornar através do currículo".

\section{O Método do Discurso do Sujeito Coletivo: Ferramenta de Identificação da Percepção dos Alunos Sobre o Processo de Ensino-Aprendizagem no Contexto de Isolamento Social}

Neste trabalho, foi utilizado como método de pesquisa o DSC, o qual possibilita o resgate de discursos coletivos de forma qualitativa, com a representação social do pensamento da coletividade por meio de um discurso-síntese que agrega os conteúdos discursivos de sentido semelhante emitido por diferentes indivíduos.

De acordo com Lefèvre (2017), o DSC surgiu da ideia de que os indivíduos, como parte da sociedade, compartilham pensamentos, crenças, percepções, valores e representações, e para que sejam captadas as suas impressões sobre determinado tema, faz-se necessário recuperar e descrever empiricamente o que as coletividades têm a dizer sobre algo.

O DSC, desse modo, almeja que cada sujeito pesquisado em um estudo contribua com sua cota de pensamento para a formação de um discurso coletivo (Lefèvre, Marques, \& Lefèvre, 2006). Contudo, o DSC não é apenas uma cópia do senso comum, ele é, na verdade, o produto de abstrações concretizadas porquanto a sua estruturação decorre de um movimento 
dialético em que os argumentos e conteúdos comuns às diferentes opiniões com sentido semelhante são ora abstraídos, ora reincorporados na categoria que os unifica.

Feito desse modo, o DSC é fruto de uma miscelânea de depoimentos individuais impregnados de vivências e experiências coletivas, que, ao passar pelo olhar atento do pesquisador munido do conhecimento das operações de abstração e conceituação do método, será transformado em produto coletivo. É válido destacar que, na elaboração do discurso do "eu coletivo", o que aparece descrito não é “. . . uma invenção, uma 'imaginação' do pesquisador, e sim uma reconstituição" (Lefèvre, 2017, p. 19), pois o método possibilita que seja gestado um texto, a partir da fala dos sujeitos, não sendo resultante da interpretação do pesquisador, mas do conjunto de fragmentos do pensamento de várias pessoas sobre um determinado assunto.

Para a obtenção do DSC, as ferramentas comumente utilizadas são as entrevistas ou os questionários individuais com questões abertas, sendo estes os instrumentos de coleta de dados escolhidos para este estudo. Assim, colhidos os depoimentos, cada um deve ser analisado individualmente, a fim de captar a essência do conteúdo que apresenta. Em seguida, são selecionados os estratos mais significativos do texto, tendo por base a pergunta a que se refere, com a finalidade de encontrar as expressões-chave, pois o que se almeja detectar é a contribuição de cada indivíduo para o pensamento coletivo e não o pensamento detalhado de cada sujeito.

Retiradas as expressões-chave de cada relato, é necessário identificar a ideia central (que pode vir a ser mais de uma). Essa figura metodológica se refere ao sentido da narrativa, demonstra o posicionamento do depoente frente ao tema sobre o qual está sendo abordado. Na seleção das ideias centrais, o pesquisador, diferente do que faz na identificação das expressõeschave, em que retira trechos fundamentais do conteúdo, sem interferir em nada no depoimento, pode usar ou não as palavras tal qual se apresentam, uma vez que as ideias podem aparecer de maneira explícita ou implícita no corpo do texto. Os sentidos, que é o que se busca captar a partir da seleção das ideias centrais, estão para além das palavras, encontrando-se, muitas vezes, nas entrelinhas.

Outra figura metodológica observada no processo de elaboração do DSC é a ancoragem, que nada mais é do que um tipo de ideia central pautada em um conhecimento ou informação preexistente no repertório do indivíduo para dar sentido a um acontecimento, fenômeno ou situação que a ele se apresenta, expressando que o seu posicionamento recebe forte influência de pensamentos difundidos pelo senso comum. Normalmente, apresentam marcas linguísticas de generalidade, tais como: todo; qualquer; nunca; sempre. Desse modo, as ideias centrais percebidas como ancoragens são aquelas que “. . . remetem diretamente a crenças ou representações fortes que são usadas para apoiar posicionamentos ou ideias" (Lefèvre, 2017, p. 33).

Após a identificação das figuras metodológicas descritas, o próximo passo para a elaboração do DSC é a categorização das respostas, que visa reunir as ideias centrais de sentidos semelhantes. Assim, dentro de uma única categoria, vários conteúdos e argumentos que compõem uma mesma opinião ou um mesmo posicionamento são compartilhados com um conjunto de pessoas. No entanto, esses diferentes conteúdos e argumentos podem ser mantidos em conjunto em um discurso porque este remete a praticamente uma única opinião ou pensamento. Desse modo, a categorização seria a expressão da soma dos depoimentos, sendo cada depoimento incluído na categoria semelhante em relação ao conteúdo.

Depois da conclusão dessas etapas, o último estágio é a elaboração do DSC propriamente dito, o qual consiste na reunião das expressões-chave cujas ideias centrais ou ancoragens apresentam sentido semelhante. Para construí-lo, é preciso apenas o uso de recursos básicos de edição do texto, encontrando depoimentos que se adaptem melhor ao início da narrativa, outros que se encaixem como conectores e outros para o fim.

O DSC deve aparecer em primeira pessoa do singular, pois o texto deve demonstrar a “. . . expressão direta do pensamento coletivo: o que o eu (coletivo) penso e não o que ele (o pesquisador na terceira pessoa) pensa que eu penso" (Lefèvre, 2017, p. 36). Ademais, é importante frisar que o produto da utilização dos recursos metodológicos do DSC não é 
exatamente o que os sujeitos pensam na totalidade, mas apresenta o discurso verbal, bem como a narrativa do que os pesquisados pensam, tornando mais visível e aparente a opinião do sujeito sobre o objeto (Alvântera \& Vesce, 2008).

Neste artigo, os dados coletados por meio de questionário enviado por e-mail aos alunos da disciplina de "Psicologia do Desenvolvimento e da Aprendizagem na Adolescência” foram organizados conforme as etapas de análise elencadas pelo método do DSC. Com essa estruturação, desejou-se formar o discurso proferido por esses alunos acerca de três questões principais, quais sejam: a experiência com o ensino remoto, a experiência com a disciplina "Psicologia e Desenvolvimento da Aprendizagem na Adolescência" e o processo de ensino-aprendizagem durante o isolamento social, em virtude da pandemia de Covid-19.

Desta feita, a fim de proceder à formulação do DSC a partir das respostas proferidas pelos alunos da referida disciplina, tendo em vista que “. . . a investigação do pensar do povo não pode ser feita sem o povo, mas com ele, como sujeito de seu pensar" (Freire, 1987, p. 64), e entendendo que a constituição do sentido se vincula intimamente à constituição do sujeito (Bakhtin, 2002), o questionário composto por cinco questões, durante o processo de análise dos dados alcançados, foi dividido em três blocos de objetivos, em que, no primeiro, buscou-se identificar a percepção dos alunos sobre a experiência com o ensino remoto, e, para tanto, foram formuladas as seguintes questões:

1 - Com suas palavras, o que você entende por ensino remoto, e como avalia a transposição do ensino presencial para a modalidade remota?

2 - Em sua opinião, quais são os principais desafios enfrentados durante a sua experiência com o ensino remoto? E como você avalia a sua participação em relação às aulas remotas síncronas e assíncronas?

No segundo bloco, pretendeu-se verificar a percepção dos alunos acerca da experiência com a disciplina "Psicologia e Desenvolvimento da Aprendizagem na Adolescência”, para tanto, foi estabelecida a seguinte pergunta:

1 - Em sua opinião, quais foram os aspectos mais relevantes da disciplina "Psicologia do Desenvolvimento e Aprendizagem na Adolescência" para a sua formação? A visão interdisciplinar que a disciplina propõe, contemplando temas que envolvem diversas áreas do conhecimento, como a psicologia, história e pedagogia, contribuiu para a sua trajetória enquanto docente?

No terceiro, almejou-se observar a percepção dos alunos sobre o processo de ensino-aprendizagem durante a pandemia, com foco em suas próprias experiências. Para isso, foram desenvolvidas as seguintes perguntas:

1 - Você considera importante ter dado continuidade ao seu curso de graduação, mesmo durante o período pandêmico e de forma remota? Comente.

2 - Se você fosse definir em três palavras o seu processo de ensino e aprendizagem durante a pandemia, quais seriam?

Nessa esteira, através das respostas apresentadas nas questões referentes a cada um dos blocos, por meio da utilização das técnicas e ferramentas mencionadas, chegamos a esses discursos:

\section{DSC sobre a experiência com o ensino remoto}

Para mim, o ensino remoto é uma tentativa de manter a rotina das aulas presenciais, em um contexto virtual. Considero que foi a melhor escolha para o momento, tendo em vista que possibilita a continuidade do ensino de modo a não gerar aglomeração, o que é fundamental para um contexto de pandemia. É um formato que apresenta vantagens e desvantagens. No geral, eu acho bem mais difícil de me concentrar, sobretudo porque não é uma 
Research, Society and Development, v. 10, n. 10, e331101018900, 2021

(CC BY 4.0) | ISSN 2525-3409 | DOI: http://dx.doi.org/10.33448/rsd-v10i10.18900

modalidade em que os alunos e os professores já estejam habituados. Creio que devem existir recursos e estratégias que tornem esse tipo de formato mais proveitoso ao ensino-aprendizagem, todavia, considerando a maneira abrupta com que foi implementado, em virtude do atual contexto, não foi idealizado de maneira adequada. Outra questão importante é o fato de essa modalidade contribuir para uma maior exclusão dos alunos das classes menos favorecidas, já que não dispõem dos recursos necessários para o aproveitamento desse tipo de ensino. Penso que, por mais que esse formato apresente algumas vantagens, como, por exemplo, a possibilidade de o aluno revisar as aulas quantas vezes precisar e no momento em que achar mais conveniente, através das aulas gravadas (assíncronas), fora de condições de emergência, não é uma opção para a substituição do ensino presencial, pois não fornece a mesma possibilidade de aprendizado para o aluno, sem contar que é muito desanimador assistir às aulas atrás de aparelhos eletrônicos, pois é muito mais cansativo, solitário e angustiante. Penso, também, que a grande exposição a que estamos submetidos às telas de computadores ou de celulares trazem muitos danos à nossa saúde e à nossa concentração. Outro ponto importante é a dificuldade de conciliação das muitas atividades e demandas acadêmicas e extra-acadêmicas. Para mim, esse tem sido um dos principais desafios, pois trabalho, família, estudo e lazer passaram a fazer parte de um único espaço. É muito complicado administrar tudo isso. Tanto que, neste semestre, tive que suprimir algumas disciplinas, porque, realmente, não consegui dar conta. Além de todas essas questões, ainda têm os problemas de ordem técnica, conexão ruim da internet, barulhos externos, ambientes não adequados para o estudo, etc. São muitos obstáculos. No entanto, apesar de estar sendo uma experiência relativamente ruim, não deixa, também, de ser interessante, sobretudo quando a disciplina tem uma abordagem bacana, trazendo discussões e temáticas que não se limitam aos seus próprios conteúdo. Nesse sentido, a utilização de palestras, por exemplo, é muito enriquecedora. Em contrapartida, muitas disciplinas caíram na qualidade de transmissão dos conteúdos, pois creio que muitas dificuldades enfrentadas pelos alunos também são vivenciadas pelos professores, e, sem dúvida, isso deve interferir no desempenho. Sobre a minha vivência em relação a tudo isso, o que posso dizer é que venho tentando passar por cima da ansiedade, do medo da doença, que é o tem gerado toda essa situação, e da sensação de impotência por não conseguir dar conta de tudo, por mais que me esforce. E, assim, vou tentando me adequar até que tudo isso passe.

\section{DSC sobre a experiência com a disciplina "Psicologia e Desenvolvimento da Aprendizagem na Adolescência"}

Tive uma experiência muito positiva com essa disciplina e com o posicionamento da professora, que mostrou a importância do elemento humano ligado ao saber, ministrando as aulas como uma verdadeira terapia em conjunto, essa postura serviu como um acalanto durante este momento tão difícil que estamos a vivenciar. Considero que a palestra do professor Levi Jucá, o qual explanou acerca da experiência de seu trabalho em sala de aula, que busca estimular o protagonismo adolescente na produção de conhecimento, foi de especial importância, contribuindo para mostrar que é possível exercer uma docência transformadora. Essa disciplina foi muito importante para minha formação. Eu posso dizer que, para mim, foi um divisor de águas, pois até o momento eu sentia um grande medo da sala de aula, medo de não conseguir, de ser incapaz de desenvolver um ensino de qualidade para os meus alunos, mas essa disciplina me mostrou que posso, sim, ser um bom profissional, independentemente das estruturas das escolas, pois compreendendo o aluno e suas fases de desenvolvimento, sob a orientação das teorias da aprendizagem de Vygotsky e Piaget, dentre outros autores abordados, tenho muito mais confiança na condução de minha docência. Entender os caminhos do processamento cognitivo e a mediação da construção do saber é uma procura constante, e sinto considerável segurança para iniciar minha atuação como docente após tocar nesse aspecto durante o curso. Nesse sentido, considero que os conhecimentos que construímos durante esse semestre foram de extrema importância, não só para minha prática docente, discente e acadêmica, mas, principalmente, para ampliar a minha percepção sobre vida, sobre o mundo. Todos esses aspectos são fundamentais, a meu ver, porque, apesar de estarmos em uma graduação de licenciatura, poucas vezes passamos por momentos de reflexões reais sobre o ensino nas escolas.

\section{DSC sobre o processo de ensino aprendizagem durante o isolamento social, em virtude da pandemia de Covid-19}

Eu considero muito importante para não me sentir psicologicamente parado no tempo, além disso, é meu sonho que está em jogo, minha garantia de um futuro decente. Não posso desistir. Confesso que pensei em parar e esperar o 
término da pandemia, mas, diante da incerteza em relação a quanto tempo permaneceríamos em isolamento, preferi dar continuidade, mesmo enfrentando muito mais dificuldades com a permanência na graduação, neste momento. Este semestre foi muito desgastante, o que me gerou muita desestabilidade psíquica. Estudar tem servido como um bom remédio para ocupar a mente, além de contribuir para a formação de uma nova rotina, no entanto, em contrapartida, a necessidade de cumprir prazos e metas estabelecidas pelas disciplinas traz muito estresse. Sinto que não estou tendo o mesmo desempenho que tinha durante as aulas presenciais, sinto-me desestimulado e percebo que meu aprendizado também sofre prejuízos, mas creio que parar com tudo também não seria uma decisão acertada. Preferi continuar dando o meu máximo, mas dentro dos meus limites. Fico mais tranquilo por ter conseguido terminar com êxito as minhas cadeiras, mas tenho consciência de que as perdas com o ensino remoto são irreparáveis, e muitas são, ainda, desconhecidas, e me assusta a possibilidade de vir a concluir um curso tão denso, que exige tanto campo, apenas na modalidade a distância. Entendo que a realidade de muitas pessoas difere da minha, e que dar continuidade ou não ao curso não é exatamente uma opção - precisam se formar, precisam das contribuições financeiras oferecidas pela universidade, precisam do contato e do convívio, mesmo que virtual, da universidade para se manterem de forma integral. Nesse sentido, a continuidade do curso é essencial, mas ainda me pergunto se essa opção é a mais acertada para que mantenhamos uma formação de qualidade, respeitando a saúde dos alunos e o momento de luto e incerteza. Infelizmente, ainda não tenho uma conclusão a respeito. Sobre o meu aprendizado, nesse período, três palavras definem: difícil, cansativo e desafiador.

Neste tópico, sob a orientação do método do DSC, o qual se configura como uma conveniente estratégia para a identificação da percepção de coletividades humanas sobre toda ordem de temas que lhes afetam, trouxemos os discursos proferidos pelos alunos sobre a forma como percebem o momento que vivenciam em seus processos educativos e de formação profissional, em um contexto de isolamento social, onde o principal mecanismo de continuidade do ensino tem sido as aulas remotas.

No entanto, é importante destacar que o DSC é apenas uma ferramenta que auxilia a demonstração do que pensam determinados grupos acerca de temas específicos, mas a identificação desse pensamento não se encerra com a apresentação da narrativa, simplesmente. É de suma importância para qualquer estudo que almeje compreender as representações sociais presentes em um dado tempo e espaço, sobre um fenômeno específico, que as narrativas sobre ele sejam analisadas dentro de uma conjuntura social, visto que o pensamento humano é, antes de tudo, um ato sociocognitivo, existindo, portanto, uma profunda conexão entre o texto (discurso) e o contexto, haja vista que, conforme nos alerta Bakhtin (2002, p. 95), “. . . a palavra está sempre carregada de um conteúdo ou de um sentido ideológico ou vivencial”, pois o pensar, ato que, em tese, antecede à palavra, “. . . não se dá fora dos homens, nem num homem só, nem no vazio, mas nos homens e entre os homens, e sempre referido à realidade" (Freire, 1987, p. 64).

Nessa perspectiva, o próximo tópico se debruçará sobre a análise desses discursos, considerando o contexto social em que estão inseridos.

\section{A Experiência do Processo de Ensino-Aprendizagem no Contexto de Pandemia: Revelando a Perspectiva Discente}

"Ninguém educa ninguém - ninguém se educa a si mesmo - os homens se educam entre si, mediatizados pelo mundo" (Freire, 1987, p. 63).

$\mathrm{Na}$ presente seção, analisaremos os discursos coletivos dos discentes, construindo nossas reflexões com base nos pontos anteriormente citados, que são: a experiência com o ensino remoto, a experiência com a disciplina de "Psicologia e Desenvolvimento da Aprendizagem na Adolescência" e o processo de ensino-aprendizagem durante o isolamento social em virtude da pandemia de Covid-19. 
Compreender a importância de considerar os discentes como sujeitos ativos no processo de ensino-aprendizagem é um ponto fundamental no desenvolvimento deste artigo, possibilitando que os educandos expressem seus pensamentos, vivências, angústias e percepções. Segundo Tardif e Lessard (2014) o trabalho docente necessita de determinadas aptidões que facilitem a aprendizagem de seus alunos, dentre eles o respeito e a capacidade de empatia. Desse modo, no decorrer do movimento de direcionar o olhar para a perspectiva discente, buscamos superar a dualidade imposta entre professor e aluno, considerando ambos igualmente importantes e protagonistas do processo, e também por acreditarmos que se torna impossível desenvolver o trabalho docente sem considerar o contexto social no qual estamos inseridos.

De acordo com Freire (1987), a concepção de educação problematizadora considera o homem como um ser histórico, em constante desenvolvimento, buscando sua humanização. Em concordância com esse entendimento, escolhemos promover uma educação em diálogo com os educandos, por compreender que o educador não é o único detentor do conhecimento, e ao mesmo tempo que educamos somos educados, transformamos e somos transformados em seres humanos melhores a partir dessa relação com o outro.

Dialogamos com uma educação crítica, que nos possibilite pensar sobre a nossa prática pedagógica, assim como proporcionar aos educandos momentos de reflexão sobre o seu processo de construção do conhecimento no decorrer da disciplina em questão, pensando sobre a sua realidade e a dos outros. Em articulação com a perspectiva apresentada por Pimenta (1999), de que o professor reflexivo se desvincula da racionalidade técnica para ter um diálogo constante entre experiências e práticas, construindo saberes que se constituem pela própria reflexão sobre e na prática, cremos que as experiências vivenciadas e apresentadas através dos DSC são relevantes para nos construirmos enquanto docentes.

Ao enfatizarmos a importância de identificar a percepção dos estudantes acerca de suas experiências no processo de ensino-aprendizagem durante a atual pandemia, faz-se fundamental que salientemos o contexto que ora se impõe à fala discente, o qual é permeado pela iminente ameaça dos indivíduos contraírem uma patologia ainda repleta de mistérios, contagiosa e de alto poder letal, e que, por todas as suas características, gera grandes dificuldades nos processos para o seu enfrentamento. Tais aspectos, sem dúvida, exerceram grande influência sobre a narrativa analisada neste trabalho, pois, como bem destaca Vigotski (1999), o produto final do pensamento de um indivíduo, seu psiquismo, é efetivamente social e socialmente condicionado.

Além disso, a pandemia de Covid-19 tem lançado luz sobre uma crise financeira que não é uma peculiaridade deste momento, especificamente, mas que é, antes de tudo, um sintoma que reflete as consequências do neoliberalismo como norteador das políticas econômicas e sociais. Tendo em vista que, de acordo com essa lógica, os investimentos sociais (saúde, educação e previdência social), embora sejam fundamentais, devem ser progressivamente defasados, já que não são satisfatoriamente lucrativos.

Convém destacar, ainda, que o impacto neoliberal para a sociedade é extremamente negativo, pois até a responsabilidade ética e social, que ainda relacionava a economia aos custos sociais, passa a não mais existir, o que acaba dificultando a vida da maioria da população, aumentando as injustiças sociais, promovendo atitudes políticas que prejudicam a vida de inúmeras pessoas e utilizando discursos democráticos que justificam suas ações antidemocráticas. Diante disso, não poderia ser diferente a visão que o atual governo brasileiro, simpático ao laissez-faire, demonstra ter acerca da escola e da universidade pública, relativizando os reais benefícios que essas instituições trazem à sociedade.

Considerando todos os retornos sociais advindos das instituições de ensino superior (IES) públicas, haja vista que são provenientes dessas instituições as melhores pesquisas científicas empreendidas no país, devemos refletir sobre os verdadeiros motivos para a antipatia que o atual governo demonstra sobre esses espaços de construção do conhecimento. Conforme Giroux (2014) são nesses lugares onde, sobremaneira, elabora-se o pensamento crítico, e, para qualquer governo que apresente posicionamentos e políticas sociais duvidosas, o pensamento crítico e reflexivo não é, nem de longe, favorável aos seus 
intentos obscuros. De acordo com Freire (2011) o ato de educar ultrapassa a mera transmissão de conhecimento, supera o intuito de ajustar e conformar os indivíduos a viver em condições adversas, mas possibilita o pleno desenvolvimento humano, onde nos transformamos diariamente em pessoas melhores, incapazes de aceitar atitudes ignorantes que prejudicam as relações sociais.

Diante desse contexto, acontece o que nem nos nossos pensamentos mais longínquos poderíamos imaginar, uma pandemia, obrigando que mudanças abruptas ocorressem em âmbito mundial, e, no nível educacional, passamos a vivenciar o ensino remoto. Segundo a percepção dos alunos e alunas, foi visto como a melhor alternativa para que fosse possível dar continuidade aos estudos, respeitando o isolamento social necessário para evitar possíveis contaminações do coronavírus, em que se compreende que esses indivíduos não negam a gravidade da pandemia e as implicações das descobertas científicas no dia a dia.

Entretanto, conforme apontado no DSC 1, os desafios do ensino remoto são inúmeros, pois acaba excluindo estudantes que não têm acesso à internet e a equipamentos para que seja possível acompanhar as aulas, o que nos faz refletir que a desigualdade de acesso e permanência na educação superior, assim como a inclusão digital, antecedem a pandemia que estamos vivenciando. Estando interligado a um projeto de sociedade que não tem como prioridade o ser humano e sua educação, como nos explica Santos (2020, p. 5), “. . . desde a década de 1980 - à medida que o neoliberalismo se foi impondo como a versão dominante do capitalismo e este se foi sujeitando mais e mais à lógica do sector financeiro -, o mundo tem vivido em permanente estado de crise'.'

Esse estado de crise criado pelo capitalismo, norteado pela lógica neoliberal, vem justificar que o investimento em uma educação de qualidade é algo impossível de acontecer, “. . . porque não existem condições financeiras para isso. ... (Santos, 2020, p. 5), legitimando a compreensão de que as grandes riquezas devam continuar dominadas por uma minoria. Dessa maneira, de acordo com o autor, a situação de crise já estava imposta, não sendo uma criação da pandemia, o que de fato ocorre é um agravamento dessa crise, nos diferentes setores, inclusive no educacional.

$\mathrm{O}$ acesso à internet e a equipamentos adequados para continuar estudando em tempos pandêmicos é um ponto extremamente relevante, mas não o único. Sendo expostas, também, as questões emocionais que estão envolvidas no processo de aprendizagem, em que se ressalta que as experiências com o ensino remoto estão intrinsecamente ligadas com aspectos negativos, como: cansaço, solidão, angústia, ansiedade, impotência, dificuldade de concentração, múltiplas demandas do ambiente doméstico e ambientes para estudar inadequados, dentre outros.

O DSC apresentado, imerso em um contexto de incertezas no qual estamos inseridos, apresenta um cenário que aponta um adoecimento mental durante a pandemia que interfere na vida estudantil. Segundo pesquisa realizada pela UFC, Universidade da Integração Internacional da Lusofonia Afro-Brasileira (UNILAB) e Instituto de Federal de Educação, Ciência e Tecnologia do Ceará (IFCE), aproximadamente 4,5 mil universitários tiveram experiências com ansiedade e depressão, que passa a fazer parte do cotidiano dos estudantes universitários cearenses, e que está em consonância com o que está sendo exposto através do discurso dos alunos e alunas da disciplina de "Psicologia e Desenvolvimento da Aprendizagem na Adolescência" (Costa \& Rodrigues, 2020).

Sabemos que o nosso processo de desenvolvimento e os aprendizados construídos estão vinculados a questões objetivas e subjetivas que permeiam a nossa existência. Os pontos citados interferem diretamente na apreensão do conhecimento, pois o processo educativo não acontece de forma fragmentada, e sim respeitando uma visão holística. Então, pensar no ensino e aprendizagem, nesse contexto, relacionados com sentimentos e condições, no mínimo adversas, torna-se extremamente desafiador. De acordo com Coutinho e Moreira (1999), Wallon nos mostra, através de sua proposta interacionista, que não podemos dissociar o ser humano dos seus aspectos biológicos e sociais, pois ambos são complementares ao desenvolvimento humano. As relações afetivas estão interligadas com o desenvolvimento cognitivo, como 
nos apresenta Lopes e Pedruzzi (2021) sobre a importância da afetividade na relação professor e estudante, e os impactos positivos no processo de ensino e aprendizagem.

O caráter social da educação é constantemente reafirmado através dos DSC, como podemos observar no DSC 1, em que as aulas remotas passam a ser compreendidas com uma qualidade inferior às presenciais, apresentando-se de uma forma desestimulante por não permitir uma interação significativa entre os sujeitos envolvidos no processo educativo. Criar vínculos afetivos que envolvem os processos educacionais se torna inviável quando o meio que está sendo proposto dificulta essa relação. Vejamos no DSC propriamente dito:

Não consigo participar das aulas com a mesma qualidade com que fazia no ensino presencial, pois não me sinto motivado a interagir sem nem mesmo ver com quem estou falando, pois a maior parte das pessoas se sente mais à vontade em assistir as aulas com a câmera desligada, e quando estamos assistindo em modo assíncrono é que essa interação não acontece mesmo, acho ainda pior. Acho que o contato social é muito importante para o aprendizado a distância, o aprender e o saber não têm a mesma alegria (DSC 1).

Nesse sentido, encontramos novamente no presente discurso a importância de compreendermos as teorias psicológicas dos processos de desenvolvimento e aprendizagem, destacando a teoria interacionista de Henri Wallon. De acordo com Coutinho e Moreira (1999), o pensamento walloniano considera como fundamental a compreensão do caráter social da educação, que ensina aos educadores que o processo de desenvolvimento ocorre na relação com o outro, bem como que as nossas relações afetivas, sociais e cognitivas estão interligadas. O DSC 1 sinaliza essa solidão que se apresenta pelas câmeras desligadas e a necessidade do contato social para que a aprendizagem aconteça em um campo que traga prazer e alegria, mas que, por conta da distância física, acaba não ocorrendo.

O DSC 3 complementa que não só a distância física está impactando a forma como os estudantes estão se relacionando com a universidade, mas a própria condição psicológica em que se encontram, como citado anteriormente. Embora compreendam a necessidade de continuar o seu curso de graduação, mesmo que remotamente, por não saberem quando a pandemia terminará, questionam se, de fato, estão experienciando um ensino de qualidade e uma formação que respeite o que sentem, a sua saúde, o luto e as incertezas que vivenciam.

As questões supracitadas não nos possibilitam respostas prontas e imediatas, mas concordamos que o primeiro passo para que esses estudantes se sintam respeitados é possibilitar que falem e nos disponibilizar a ouvi-los. É vital que o trabalho docente também seja um trabalho de escuta, que ultrapasse a possibilidade auditiva, mas que, como nos explica Freire (1996, p. 45), disponha-se, de maneira permanente, a abrir-se “. . . à fala do outro, ao gesto do outro, às diferenças do outro".

Desse modo, mesmo através do ensino remoto, com todos os desafios que lhes são inerentes, no tocante à criação de vínculo afetivo para o estabelecimento do aprendizado, aspecto que, conforme o psicanalista português João dos Santos (2017), Holanda e Cavalcante (2013) e Holanda (2016), é de extrema relevância para um processo de ensino-aprendizagem verdadeiramente eficaz, pois cremos que, a depender da metodologia utilizada pela professora ou professor que está ministrando as aulas, mesmo nessa modalidade de ensino, tal elemento pode ser minimamente alcançado.

Outro ponto que merece destaque na experiência vivenciada pelos alunos na disciplina anteriormente citada foi a utilização de seminários que abordaram temas extracurriculares, que contribuíram para o alargamento de possibilidades de intercruzar elementos de diferentes campos do conhecimento educacional, proporcionando discussões interdisciplinares, a partir de uma visão holística dos múltiplos aspectos que podem envolver a educação. Tal experiência, é importante mencionar, foi muito apreciada pelos alunos, conforme demonstra o trecho do discurso dos alunos, que veremos a seguir: 
No entanto, apesar de estar sendo uma experiência relativamente ruim, não deixa, também, de ser interessante, sobretudo quando a disciplina tem uma abordagem bacana, trazendo discussões e temáticas que não se limitam aos seus próprios conteúdos. A utilização de palestras, por exemplo, é muito enriquecedora, nesse sentido (DSC 1).

Conforme Freire (1996), as diferenças e particularidades de cada aluno é elemento indissociável do seu processo de formação. Nessa perspectiva, cremos que uma relação de ensino-aprendizagem que se resuma à simples transmissão de conteúdos pertencentes à grade curricular, que não se preocupa em envolver o aluno em outros assuntos que contribuam para pensar a sua própria condição de sujeito no mundo, não favorece o estímulo necessário ao desenvolvimento do pensamento crítico. E a criticidade de pensamento é primordial para a execução de disciplinas que fazem parte do currículo das licenciaturas, que é o caso da disciplina aqui citada, pois os sujeitos que a compõem atuarão em breve como professoras e professores da educação básica, e, portanto, levarão muitas de suas experiências de aprendizados na graduação para o futuro exercício de suas docências.

De acordo com o pedagogo norte-americano Henry Giroux, precisamos incorporar no nosso fazer pedagógico o pensamento crítico, para que seja possível criar cidadãos que não se conformem com as injustiças sociais impostas e tenham consciência dos seus direitos. Quando recebemos uma formação que se limita a uma mera transmissão de conhecimento, memorização e conformismo, deixamos de refletir, de nos posicionar, de ser protagonistas da nossa história, não conseguindo construir uma base teórica que auxilie a nossa prática pedagógica, e assim a educação acaba sendo silenciada e impedida de promover atitudes e ideias que sejam contrárias a um sistema opressor (Giroux, 2019).

Desse modo, compreendemos que a educação não é neutra, por isso, enquanto educadores, devemos defender a ética universal dos seres humanos, promovendo uma educação que considere a formação humana, embora saibamos que tal função social é repleta de desafios, traduzindo-se em um árduo caminho a ser percorrido, sobretudo diante de governos com tendências fascistas.

Contudo, pequenas conquistas alcançadas nessa caminhada, tal como perceber, através do relato dos discentes, que conseguimos nos aproximar dos estudantes de uma forma inspiradora, contribuindo para suas reflexões sobre quem são, que profissionais desejam ser e que tipo de educação desejam promover quando estiverem em sala de aula, mesmo diante das inúmeras dificuldades que irão se apresentar, são pontos extremamente relevantes para que continuemos a postos em nossa trajetória. Vejamos:

A abordagem interdisciplinar, que foi a principal característica dessa disciplina, contribuiu, em grande medida, para ampliar o meu olhar sobre o processo de ensino-aprendizagem, mostrando o quanto é importante me empenhar em um tipo de educação que não se restrinja à transmissão dos conteúdos formais, demonstrando a correlação entre a formação acadêmica com a formação humana. A disciplina me apresentou questões e provocações que me levaram a pensar minha formação enquanto educador de forma mais humana. Creio que os conteúdos aprendidos nas aulas e as discussões interdisciplinares através das palestras ministradas, as quais possibilitaram discussões interdisciplinares, aguçando o meu olhar para outras questões que nem sempre são aquelas que devem ser diretamente trabalhadas pelo currículo, mas que são extremamente importantes para o alcance do aprendizado, ainda mais numa fase da vida tão incompreendida quanto a adolescência, irão auxiliar na forma como irei encarar a minha docência e, sobretudo, o aluno dentro do processo de ensino-aprendizagem (DSC 2). 
A abordagem interdisciplinar citada como uma característica da disciplina foi muito enfatizada pelos alunos, tendo em vista que esse corpo discente é bastante heterogêneo, contando com pessoas provenientes de diversos cursos de licenciaturas, tais como letras, história, dança, teatro, matemática e biologia, dentre outros. Desse modo, a preocupação da disciplina em abordar temas de diferentes campos do conhecimento, relacionando-os à educação, contribuiu, sobremaneira, para o engajamento da turma nos momentos de discussão, criando conexões entre indivíduos que, em outras situações, dificilmente discutiriam e construiriam, juntos, conhecimento acerca do fazer educacional e de seus próprios papéis nesse processo.

Cientes de que não existe uma ciência absoluta, que consiga compreender as complexidades da realidade, cremos ser de grande relevância a existência desse diálogo entre os diferentes campos de conhecimento, por essa razão, optamos por seguir uma perspectiva transdisciplinar. De acordo com Dosse (2003), a transdisciplinaridade permite que as áreas do conhecimento não se sobreponham umas às outras, mas que trabalhem em uma complementaridade, relacionem-se, dialoguem e, assim, construam um novo conhecimento.

No DSC 2, também é citado que os conteúdos trabalhados, no decorrer da disciplina e através das palestras ministradas por nossos convidados, trouxeram discussões que nem sempre são trabalhadas diretamente pelo currículo. Essa forma de organização da disciplina tem em si uma intencionalidade pedagógica, que é pensar o currículo para além do que as teorias tradicionais propõem. Silva (2005) nos explica que mais importante do que desenvolver técnicas para compreender o currículo, é possibilitar a compreensão dos porquês do currículo.

Dentre outras questões, através dos discursos analisados, observamos que são inúmeros os desafios que se apresentam na vida pessoal e acadêmica dos nossos alunos e alunas, que, inevitavelmente, prejudicam a sua aprendizagem. Identificamos que, para eles, o ensino remoto se apresenta como uma estratégia para continuar estudando devido à necessidade de isolamento social, mas que não supre satisfatoriamente todas as suas demandas enquanto aprendentes, aspecto enfatizado no trecho do DSC1, em que os discentes expressam que “. . . fora de condições de emergência, o ensino remoto não é uma opção para a substituição do ensino presencial, pois não fornece a mesma possibilidade de aprendizado para o aluno".

Torna-se importante ressaltar que continuar estudando, mesmo que de forma remota, também foi visto de uma forma positiva, pois eles não poderiam ficar estagnados até que a pandemia terminasse, porque não temos como precisar a data em que esse fenômeno patológico terá um fim. Então, mesmo vivenciando experiências de abalos emocionais, que se refletem em desânimo, ansiedade e tristeza, preferiram dar continuidade ao seu curso de graduação.

Para a escolha dessa decisão, algumas razões aparecem com maior frequência na narrativa dos nossos protagonistas, dentre as quais: necessidade de ocupar a mente estudando; criar uma rotina; dependência da contribuição financeira concedida pela universidade; proximidade da formatura; ideia da graduação como um sonho a ser realizado, por consistir na principal possibilidade de melhoria de vida. Todavia, a despeito de suas escolhas, foram categóricos em afirmar que têm consciência das perdas irreparáveis na qualidade da sua formação, demonstrando grande preocupação em ter que concluir os seus cursos de licenciatura nesse formato, haja vista a densidade de conteúdos que precisam ser trabalhados e discutidos, bem como pelos conhecimentos que só poderão ser construídos indo a campo.

Por todas as questões que foram levantadas neste estudo, consideramos fundamental compreender como os discentes perceberam e vivenciaram o ensino remoto, refletindo sobre a relação de ensino e aprendizagem em tempos pandêmicos. As experiências que vivenciamos com a disciplina de "Psicologia do Desenvolvimento e Aprendizagem na Adolescência" são extremamente relevantes para o trabalho efetivo em sala de aula, por possibilitar esse entendimento sobre o processo do desenvolvimento humano e a construção do conhecimento. Através dos discursos apresentados neste artigo, foi possível, também, repensarmos a nossa prática pedagógica, pois, concordamos com Freire (1996, p. 18), que “. . . é pensando criticamente a prática de ontem que se pode melhorar a próxima prática". 


\section{Considerações Finais}

$\mathrm{O}$ trabalho apresentou as ações que realizamos para sistematizar as principais teorias psicológicas dos processos de desenvolvimento e aprendizagem junto aos cursos de licenciatura ofertados pela UFC, no sentido de retratar o desafio de desenvolver uma prática pedagógica no ensino remoto que supere o simples acesso às informações, para a transformação dos conhecimentos em promoção do crescimento humano.

Tal objetivo nos desafiou a repensar o currículo em ação através da dinâmica da sala de aula e a ficarmos atentos às nossas posturas como professores, conforme podemos observar nas percepções expostas pelos alunos através do DSC, as quais explicitaram a proficuidade de levar em conta a desmotivação apresentada pelos alunos dos cursos de licenciatura e as dificuldades encontradas para estudar, sobretudo no período da pandemia, em um mundo de aceleradas mudanças e incertezas, que, muitas vezes, vêm acompanhadas da exclusão e perdas de familiares, dos colegas de estudo e de trabalho.

Diante do exposto, consideramos pertinente avaliar as nossas práticas pedagógicas, bem como se os conteúdos ministrados na disciplina faziam sentido e tinham significado para os alunos, uma vez que a aprendizagem depende do interesse, da atenção e motivação de seus estudantes.

Observamos que a opção pela interdisciplinaridade, os estudos das teorias psicológicas do desenvolvimento e aprendizagem, a realização do seminário com temáticas extracurriculares relacionadas às problemáticas do momento atual e o "dar voz" a todos os participantes da disciplina nos possibilitou atingir o intuito da mesma, voltada para a formação de professores, demonstrando o quanto a educação tem forte influência na construção das estruturas individuais e, por via de consequência, na formação de novas gerações.

Ao propormos aos alunos as temáticas, convidando-os a raciocinar de modo reflexivo, percebemos que a ação educativa tem o poder de viabilizar a constituição de estruturas cognitivas e socioafetivas no sujeito, contribuindo para a ascensão de um ser eminentemente social e de personalidades mais crítica e autônoma, com habilidade de viver em um mundo em constante mudança com mais humanidade, de modo a não conceder espaço para qualquer autoritarismo.

Consideramos que o presente artigo não intenciona ser uma contribuição final sobre os complexos processos que envolvem o ensino e a aprendizagem no contexto de pandemia, em estudos futuros pretendemos aprofundar os conhecimentos trazidos pelas teorias psicológicas dos processos de desenvolvimento e aprendizagem, com ênfase no desenvolvimento da inteligência e afetividade.

\section{Referências}

Alvântara, A. M. \& Vesce, G. E. P. (2008). As representações sociais no discurso do sujeito coletivo no âmbito da pesquisa qualitativa. Anais do VII Congresso Nacional de Educação, Curitiba. http://www.pucpr.br/eventos/educere/educere 2008/anais/pdf/724_599.pdf.

Bakhtin, M. (2002). Marxismo e filosofia da linguagem. Hucitec.

Costa, A. \& Rodrigues, R. (2020). Mais de 4,5 mil universitários apontam episódios de ansiedade ou depressão durante a pandemia. Diário do Nordeste. https://diariodonordeste.verdesmares.com.br/regiao/paywall-7.100?aId=1.2967971.

Coutinho, M. T. C. \& Moreira, M. (1999). Psicologia da Educação - um estudo dos processos psicológicos de desenvolvimento e aprendizagem humanos, voltado para a Educação: ênfase nas abordagens interacionistas do psiquismo humano. Editora Lê.

Dosse, F. (2003). Uma transdisciplinaridade. In: DOSSE, François. O império do sentido: a humanização das Ciências Humanas. Edusc.

Freire, P. (1996). Pedagogia da autonomia: saberes necessários à prática educativa. Paz e Terra.

Freire, P. (1987). Pedagogia do oprimido. Paz e Terra

Freire, J. A. C. F. (2011). Mulher e Educação: Do lar à Docência. Universidade Estadual do Ceará. (Monografia)

Giroux, H. (2014). Henry Giroux e a ascenção do chamado neo-liberalismo. Entrevista concedida a Michael Nevradakis, 20 out. 2014. https://tarcisio.wordpress.com/2014/10/20/henry-giroux-e-a-ascencao-do-chamado-neo-liberalismo. 
Research, Society and Development, v. 10, n. 10, e331101018900, 2021

(CC BY 4.0) | ISSN 2525-3409 | DOI: http://dx.doi.org/10.33448/rsd-v10i10.18900

Giroux, H. (2019). A crise da Escola é a crise da democracia. Entrevista concedida ao El País, 14 maio $2019 . \quad$ El País. https://brasil.elpais.com/brasil/2019/05/09/internacional/1557407024_184967.html.

Holanda, P. H. C. \& Cavalcante, M. J. M. (2013). Por uma psicologia da cognição do afeto, a favor da infância e da subjetividade. In: Holanda, P. H. C. et al. (Org.). História da Educação Comparada: missões, expedições e intercâmbio. Edições UFC.

Holanda, P. H. C. (2016). Ideias Psicopedagógicas e Instituições de Educação e Saúde numa Abordagem Santiana. In: Holanda, P. H. C. \& Morato, P. J. P. (Org.). Pedagogia Terapêutica Diálogos e estudos Luso-brasileiros sobre João dos Santos. Edições UFC.

Lefèvre, F. (2017) Discurso do Sujeito Coletivo: Nossos modos de pensar, nosso eu coletivo. Andreoli.

Lefèvre, F., Marques, M. C. C. \& Lefèvre, A. M. C. (2006). O sujeito coletivo que fala. Interface - comunicação, saúde, educação, Rio de Janeiro, v. 10, n. 20, p. 517-524. https://www.scielo.br/j/csc/a/bLYcq4qWYBJnrfZzbVrZmJh/?lang=pt..

Lopes, M. J. M. \& Pedruzzi, A. D. N. (2021). O afeto na relação Professor e Estudante e sua influência no Processo de Ensino e Aprendizagem. Research, Society and Development. 10 (9), 1-15. doi 10.33448/rsdv10i9.17775

Pimenta, S. G. (1999). Formação de professores: identidade e saberes da docência. In: Pimenta, S. G. (Org). Saberes pedagógicos e atividade docente. Cortez Editora.

Santos, B. D. S. (2020) A cruel pedagogia do vírus. Edições Almedina, S.A.

Santos, J. D. (2017). A Casa da Praia: o psicanalista na escola. Edição de Product Solutions Catalysis Ltd.

Silva, T. T. D. (2005). Documentos de identidade: uma introdução às teorias do currículo. Autêntica.

Tardif, M. \& Lessard, C. (2014). O ofício de Professor. Editora Vozes.

Vygotsky, L. S. (1999) Psicologia da arte. Martins Fontes. 